\title{
The Unequal Distribution of International Climate Finance Flows and Its Underlying Drivers
}

\section{Jamie Rickman ( $\nabla$ jamie.rickman.14@ucl.ac.uk)}

University College of London (UCL)

\section{Sumit Kothari}

UCL https://orcid.org/0000-0002-4560-1059

\section{Francesca Larosa}

Institute of Sustainable Resources, University College London

Nadia Ameli

University College London https://orcid.org/0000-0002-6728-9190

\section{Article}

\section{Keywords:}

Posted Date: February 9th, 2022

DOI: https://doi.org/10.21203/rs.3.rs-1188981/v1

License: (c) (i) This work is licensed under a Creative Commons Attribution 4.0 International License. Read Full License 


\title{
The Unequal Distribution of International Climate Finance Flows and Its Underlying Drivers
}

\author{
Jamie Rickman ${ }^{1}$, Sumit Kothari ${ }^{1}$, Francesca Larosa ${ }^{1}$, Nadia Ameli ${ }^{1}$ \\ ${ }^{1}$ Institute for Sustainable Resources, University College London \\ * corresponding author: jamie.rickman.14@ucl.ac.uk
}

\begin{abstract}
Developed country pledges to provide finance to developing countries for their mitigation actions and adaptation needs sit at the heart of international climate cooperation. Present commitments are deficient both in terms of their quantity and their distribution among developing countries. Using wind and solar energy financing data we highlight the unequal distribution of international climate finance among developing countries and identify the determinants of investment suitability that drives the flows of non-aid climate finance more generally. Economic capabilities, business environment, climate policy environment and electricity access levels are significant drivers of private finance flows, whereas public finance is driven chiefly by domestic climate policy ambition since the Paris Agreement. Climatevulnerable countries however struggle to access finance, with path dependency in investment flows further reinforcing existing inequalities. Forthcoming deliberations on quantifying longterm finance targets should thus incorporate mechanisms to distribute finance more equitably to meet country-specific needs and priorities.
\end{abstract}

\section{Main}

The pledge to mobilise $\$ 100$ billion a year by 2020 to support climate change mitigation and adaptation actions ('climate finance') in developing countries, made as part of the Copenhagen Accord in 2009, was a landmark moment in international climate cooperation ${ }^{1}$. The 2015 Paris Agreement confirms the pledge and extends the collective mobilisation goal to $2025^{2}$. This commitment, built on the principle of equity, recognizes the common but differentiated responsibility of countries to address climate change, given their different track records on historical emissions and economic development, and the varying capacities to adapt to uneven climate impacts ${ }^{3}$. It has formed the basis for international climate cooperation and the participation of developing countries in decarbonising their growing economies to mitigate climate change. 
This pledge has not been honoured. The recent plan to deliver climate finance to developing countries forecasts that financial flows will reach the promised levels only in $2023^{4}$. Meanwhile there are disagreements on the accounting of funds delivered towards the $\$ 100$ billion target $^{5}$ arising from the stated pledge to source finance "from a wide variety of sources, instruments and channels" ${ }^{2}$. Inconsistent reporting by countries due to the lack of internationally agreed standards and discord over the equivalence of funds provided, such as through grants, loans, export credits and guarantees, have hindered the measurement of climate finance provided to developing countries ${ }^{6}$. Beyond the amount of climate finance, there is also a significant divergence from the collectively agreed principles stated in Article 9 of the Paris Agreement that describe the intended nature of such flows. These disparities concern, for instance, the rebranding of existing developmental aid as climate finance, the climate-centricity of funding as opposed to climate co-benefits, the imbalance of funds targeting climate change mitigation and adaptation, and the support of country-driven strategies, local priorities, and needs-based financing over profit seeking investments ${ }^{5,6}$.

While annual flows of $\$ 100$ billion are indeed insufficient ${ }^{7,8}$ to meet the needs of developing countries, the distributive aspect of these flows is largely unexamined. The current institutional structure for channelling finance is hugely disparate. Only a small amount of funds are directed by centralised UN institutions such as the Green Climate Fund ${ }^{6}$, whereby developing countries' representation ensures that funding is aligned with countries' priorities and is distributed more equitably 9 . In contrast, developing countries have limited agency over bilateral, multilateral and private finance flows ${ }^{10}$. As a result, the quantity and direction of flows remains both inadequate and unpredictable for developing countries to account for in their domestic climate plans. Within the current architecture of climate finance ${ }^{11}$, it is thus important to understand what drives these flows and how investments can be channelled more equitably than at present - the majority of climate finance flows are directed towards middle-income countries, while low-income and vulnerable countries are under-served ${ }^{12}$. Furthermore, private finance is expected to play a major role in funding climate change mitigation and adaptation actions; analysis from COP26 estimates that $70 \%$ of global mitigation financing can be provided by the private sector ${ }^{13-15}$. Private finance hence represents a large pool of resources and there is limited possibility of controlling its direction purely through institutional mechanisms at the international level ${ }^{6,16}$. It is therefore crucial that countries identify how best to attract these funds.

This study examines the case of wind and solar energy finance to understand the distribution and determinants of international public and private investment. Mitigation finance currently dominates the landscape of global climate finance and specifically these two renewable 
energy technologies attract over $50 \%$ of international finance flows ${ }^{17}$. In addition, these flows are dominated by private sector investments and commercial loans, making them a good representation of mitigation finance in general where $54 \%$ of finance is sourced from private sources. Even in the case of adaptation financing, only $21 \%$ of financing comes from grants, and the majority of finance is sourced as market-rate debt from public finance institutions. Our dataset, composed of both public and private flows, thus adequately represents the bulk of non-aid climate finance flows globally, both at present and possibly in the future, given recent commitments $^{12,18,19}$. We examine the distributional dimension of these flows, in terms of capacity additions, across upper middle income (UMI), lower middle income (LMI), and low income (LI) countries ${ }^{20}$ and use dynamic network models to identify the factors that best explain their destinations. In addition, we examine these flows before and after the Paris agreement, since it resulted in stronger domestic climate policies supporting nationally determined contributions (NDC), new emphasis upon aligning finance with climate goals and clear policy signals to the investment community.

\section{Investments are distributed unequally across countries}

Using the Bloomberg New Energy Finance (BNEF) database we construct a project-level dataset of wind and solar capacity additions made between 2010 and 2019 in which finance flowed across borders into a developing country of the Global South. Finance flows prior to the Copenhagen Accord of 2009 were negligible, with annual capacity additions totalling less than half a GW (Fig. S1). Our analysis covers 1,156 projects comprising $46 \mathrm{GW}$ of renewable capacity installed in 76 countries using international public and private finance. Although the coverage of wind and solar projects is not exhaustive, BNEF is considered the most comprehensive database for renewable assets. China and India are excluded from the analysis due to the atypical size of their renewables markets ${ }^{21}$; they accounted for over $80 \%$ of added solar and wind capacity in the last decade and would obscure investment trends in the rest of the developing world.

In terms of overall investment, the period following the Paris agreement saw an almost twofold increase in wind and solar installations using international finance, growing from $16.1 \mathrm{GW}$ in the pre-Paris era (2010-2015) to $30.1 \mathrm{GW}$ in the post-Paris era (2016-2019) (Table 1). Private finance dominated financial flows across both periods, delivering $65 \%$ of capacity additions pre-Paris and $60 \%$ post-Paris. However, the distribution of financial flows across income groups is highly unequal. $94 \%$ of capacity additions by the public sector were received by UMI and LMI countries pre-Paris with only $6 \%$ going to LI countries, who represent $18 \%$ of all countries receiving funds. In the post-Paris era, their share of public finance improves only 
marginally, in spite of the fact that new finance channels were opened into 8 low-income African nations (Mali, Uganda, Burundi, Mozambique, Niger, Eritrea, Madagascar and Gambia). Private sector financial flows are distributed even more unequally with just $0.1 \%$ of finance reaching $\mathrm{LI}$ countries pre-Paris and $2.3 \%$ post-Paris, while $\mathrm{LI}$ countries represent $9 \%$ (pre-Paris) and 20\% (post-Paris) of all countries receiving private finance. Furthermore, UMI and LMI countries receive relatively equal shares of public finance, while the private sector provides almost twice as much finance to UMI countries (Table 1).

Pre-Paris (2010-2015)

Post-Paris (2016-2020)

\begin{tabular}{|c|c|c|c|c|c|c|c|c|}
\hline & $\begin{array}{l}\text { Capacity } \\
(\mathrm{GW})\end{array}$ & $\begin{array}{l}\text { Capacity } \\
\text { (\% of total) }\end{array}$ & $\begin{array}{c}\text { Countries } \\
\text { (Count) }\end{array}$ & $\begin{array}{l}\text { Countries } \\
\text { (\% of total) }\end{array}$ & $\begin{array}{c}\text { Capacity } \\
\text { (GW) }\end{array}$ & $\begin{array}{l}\text { Capacity } \\
\text { (\% of total) }\end{array}$ & $\begin{array}{c}\text { Countries } \\
\text { (Count) }\end{array}$ & $\begin{array}{l}\text { Countries } \\
\text { (\% of total) }\end{array}$ \\
\hline \multicolumn{9}{|l|}{ Public } \\
\hline UMI & 2.47 & 44.3 & 14 & 35.9 & 5.95 & 48.3 & 17 & 32.7 \\
\hline LMI & 2.79 & 50.1 & 18 & 46.2 & 5.61 & 45.6 & 22 & 42.3 \\
\hline $\mathrm{LI}$ & 0.31 & 5.6 & 7 & 17.9 & 0.75 & 6.1 & 13 & 25.0 \\
\hline Total & 5.57 & & 39 & & 12.31 & & 52 & \\
\hline \multicolumn{9}{|l|}{ Private } \\
\hline UMI & 7.29 & 69.4 & 19 & 43.2 & 11.19 & 63.3 & 20 & 38.5 \\
\hline LMI & 3.21 & 30.5 & 21 & 47.7 & 6.08 & 34.4 & 21 & 40.4 \\
\hline LI & 0.01 & 0.1 & 4 & 9.1 & 0.41 & 2.3 & 11 & 21.2 \\
\hline Total & 10.51 & & 44 & & 17.68 & & 52 & \\
\hline
\end{tabular}

Table 1. Capacity additions from public and private sources across income groups pre- and post-Paris. Table summarises total wind and solar capacity additions from public and private international sources made in a pre-Paris (2010-2016) and post-Paris (2016-2019) period, grouping 76 developing countries of the global South into income groups; upper middle income (UMI), lower middle income (LMI) and low income (LI).

The distribution of finance across countries is also highly skewed, with a small fraction receiving the majority of capacity additions (Fig. 1). Between 2010 and 2019, 46\% of capacity additions from public sources go to just three countries: Mexico, Morocco and Argentina, and the private sector similarly directs $54 \%$ of its capacity additions into Mexico, Vietnam and South Africa. While there is a degree of correlation between flows of public and private finance, e.g., Mexico is a top recipient from both, there are also some relevant differences. Public and private finance channels overlap in Latin America and East Asia, but private finance flows are weaker in the poorer nations of East and West Africa where public finance is more prominent (Fig. 1). 


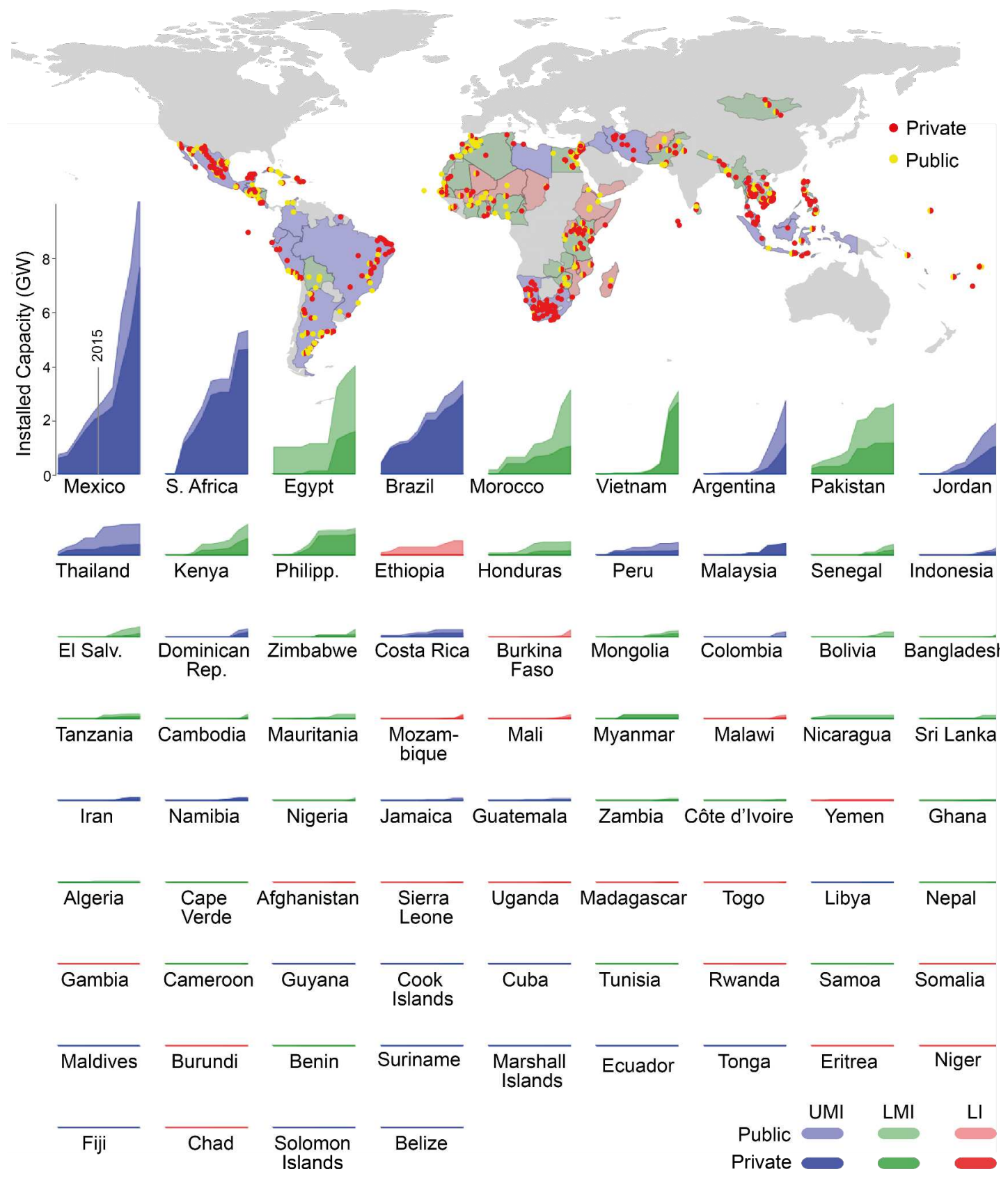

Fig. 1: Distribution of public and private international finance across the developing world and over time. Map (top) shows countries included in the analysis color-coded according to their income group; upper middle income (UMI), lower middle income (LMI) and low income (LI). The locations of projects developed between 2010 and 2019 are shown as circles color-coded according to whether the funding came from public sources (yellow), private sources (red) or both (half-yellow, half-red). Charts (bottom) show cumulative wind and solar capacity additions per country between 2010 and 2019 from international sources.

The confluence of international public and private flows into richer countries and their divergence into the poorest, suggests an underlying set of shared and differentiated drivers. To identify these, we develop a network model based on discrete choice theory, such that the probability of investment by a public or private actor is driven by a set of country-specific features (Methods). Using BNEF's investment data we explored a number of variables (Table S1) and identified a set of features that are significant in explaining the flows of public and private finance. We also found that key results are technology agnostic (Table S2). 


\section{Investment suitability drives international private finance}

The distribution of private finance across the developing world is shaped by four features characterising a country's suitability for investment: Economic fitness or capabilities ${ }^{22}$ (EF); the business environment ${ }^{23}$ (EDB); renewable energy policies ${ }^{24}$ (RISE); and electricity access $^{25}$ (Elec Access). Statistical significance testing ( $p$-values) and a model accuracy score $(\rho)$, giving the correlation between simulated and empirical distribution of investments, demonstrate that these features drive private finance flows both pre- and post-Paris (Fig. 2, Table S3). This suggests that countries with a better macroeconomic, governance and policy environment are perceived as relatively low risk by investors, leading to private investment. Moreover, the Climate Vulnerability of a country (ND Vuln), representing a country's exposure, sensitivity and capacity to adapt to climate change impacts ${ }^{26}$, is negatively correlated with each investment suitability feature (Fig. S2) and appears an impediment to the flow of private finance.

The coefficient $\theta$ (scaled to between 0 and 1 ) indicates the strength of the relationship between each feature and a country's investment suitability. A favourable policy environment for renewable energy is a consistently strong attractor for investment both pre- and postParis. However, the strength of other features changes from pre- to post-Paris, suggesting that the impact of the adoption of the Paris agreement and the enduring technological cost dynamics ${ }^{27}$ have shifted investor priorities. The business environment feature increases in strength post-Paris, while the economic fitness feature decreases. This is a potentially important change for developing countries, suggesting that short-term policy actions to improve the business environment for renewables can boost private investment despite wider macroeconomic shortcomings. Moreover, access to electricity plays a greater role in investor decision-making post-Paris (increase in model accuracy, $\rho$ ), highlighting the importance of existing government programmes in developing countries to increase energy access under SDG7 goals. However, this also means that countries with large rural populations that struggle to achieve grid-based electrification, which many domestic energy access programmes focus on, are disadvantaged in accessing private finance. 

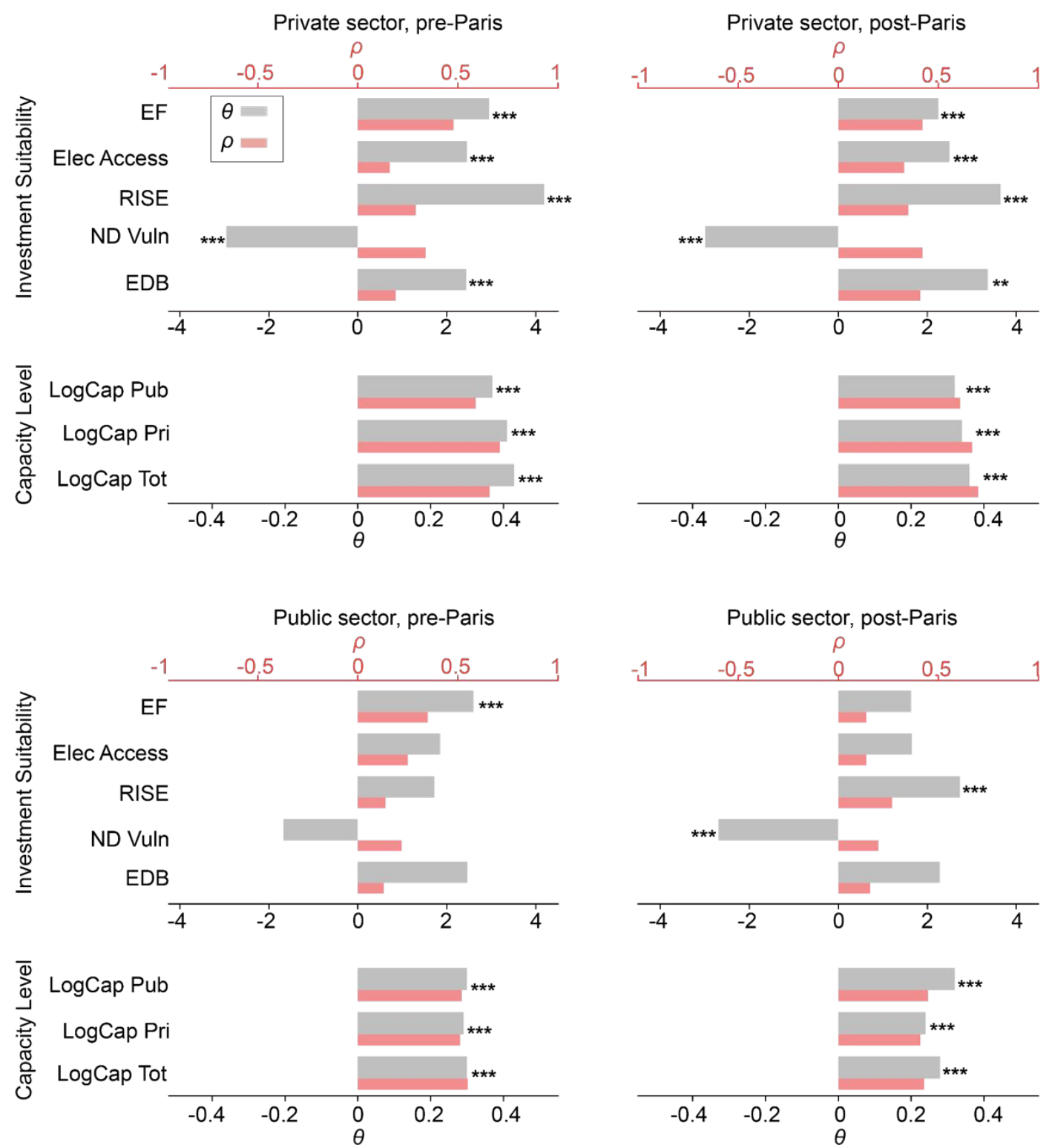

Fig. 2: The drivers of public and private sector investment pre- and post- Paris. Results of the conditional logit models based on 5 investment suitability and 3 capacity level features for public and private sector investment activity pre-Paris (2010-2016) and post-Paris (2016-2020). Parameter estimate, $\theta$, model accuracy score, $\rho$ and $p$ values are shown. *significant at $p<0.01,{ }^{* *}$ significant at $p<0.001,{ }^{* *}$ significant at $p<0.0001$.

Grouping countries by income level reveals that $\mathrm{LI}$ countries score lowest on each investment suitability features (Fig. 3). In addition, while UMI and LMI countries have seen their average RISE scores jump after the Paris agreement, LI scores have failed to improve; implying they have not prioritised renewables over other development imperatives. Meanwhile, LI countries display the highest vulnerability to climate change impacts (Fig. 3), and this is expected to increase in the future ${ }^{28}$. Low levels of investment suitability, further negatively influenced by climate vulnerability, creates a perception of LI countries as high-risk destinations for international finance. This highlights a dual tragedy for poor and vulnerable nations. Their high-risk status for private investors creates an automatic barrier for investments and 
increases the cost of capital ${ }^{29}$; while climate change impacts will generate economic, social and political externalities that will negatively influence sovereign risk and credit ratings ${ }^{30}$, leading to a 'climate investment trap'29 of chronically insufficient private funding.

Pre-Paris

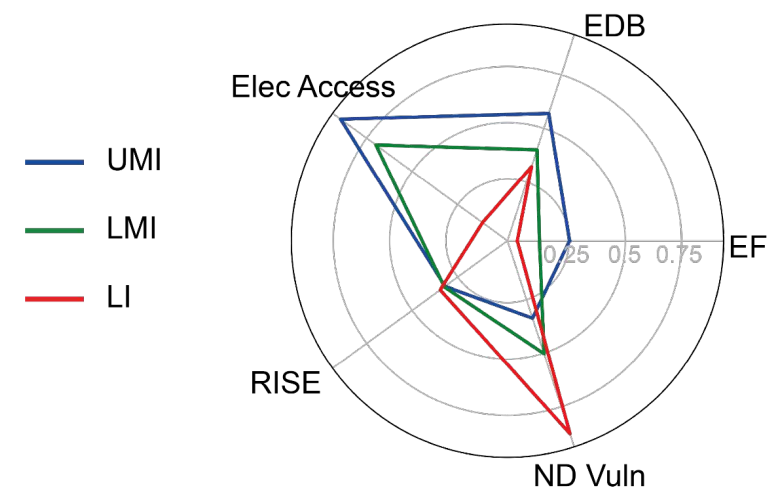

Post-Paris

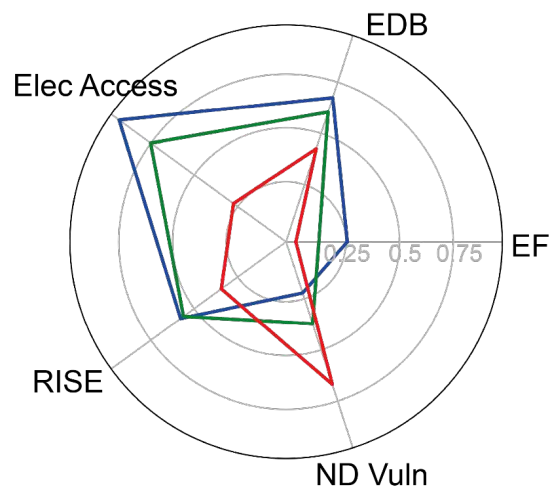

Fig. 3: Average investment suitability scores per income group. Charts show Investment suitability features averaged across income groups; upper middle income (UMI), lower middle income (LMI) and low income (LI) and in two time periods; pre-Paris (2010-2015) and post-Paris (2016-2019). Features are scaled to lie between 0 and 1. Elec Access (\% of the population with access to electricity), EDB (Ease of Doing Business), EF (Economic Fitness), ND Vuln (vulnerability to climate change), RISE (Regulatory Indicators for Sustainable Energy).

\section{Public finance supports local climate policy action}

In contrast to private finance, international public flows are not observed to be as sensitive to investment suitability features, reflecting the growing emphasis on international public finance to support climate investments in developing countries ${ }^{31}$. In the pre-Paris era, economic fitness was the only feature to appear as a statistically significant driver of public flows. Macroeconomic capabilities were thus a criterion for investment, possibly to ensure the recovery of financing provided. The only statistically significant driver of public finance in the post-Paris era is the renewables policy feature, suggesting that domestic climate policy action was supported by public institutions. However, investment suitability features continue to exert an influence, as confirmed by the model accuracy scores, and explain the historical skew in financial flows (Table 1, Fig. 1). Thus the mission-oriented activity ${ }^{32,33}$ of international public finance increases post-Paris but still remains relatively weak, evidenced by the struggle of climate vulnerable countries to access finance (Fig. 2).

\section{A track record of investments creates path dependency}

In addition to investment suitability, the other significant driver of financial flows has been the track record of wind and solar investments as measured by their cumulative installed capacity. Investment decisions are thus path dependent ${ }^{34}$. Path-dependency can be explained by endogenous feedbacks ${ }^{35}$ within a growing renewables sector, where technological and 
financial learning bring down financing and development $\operatorname{costs}^{36}$, signal confidence to the market and attract further investments in a virtuous cycle. Attributing existing installed capacity separately to public and private sector funding, we observe that path-dependency internal to each sector is the dominant driver of flows. Therefore, countries that have historically received greater private or public investments are more likely to receive similar funding in the future (Fig. 4).

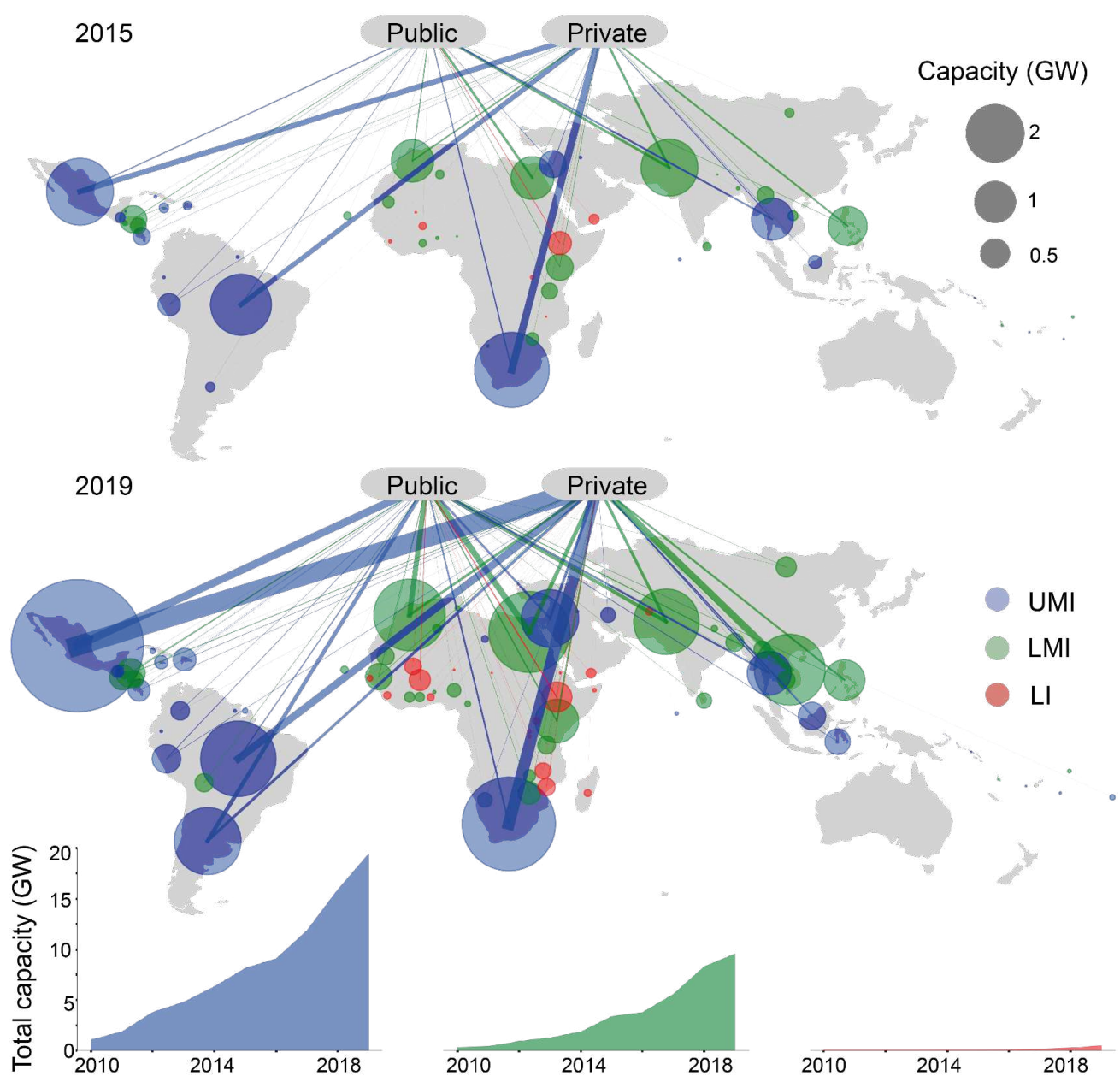

Fig. 4: Inequalities in finance across income groups perpetuate over time due to path-dependency. (Top) Maps depict finance flows to countries from public and private sources in 2015 and 2019. Size of circles represents total wind and solar capacity installed by international public and private sources. Width of links represents installed wind and solar capacity by sector. (Bottom) Plots of cumulative installed capacity from public and private sources across income groups; upper middle income (UMI), lower middle income (LMI) and low income (LI).

Path-dependency in the destination of private investments further embeds inequalities in financial flows by reinforcing the investment unsuitability of poorer countries and impeding any systemic shift in funding patterns. It also exacerbates the tension between the role of the public actors as market-creators in high-risk countries ${ }^{32,37}$ and as prudent financial institutions ${ }^{31}$. Path-dependency thus creates a new mechanism of the climate investment trap whereby historical inequalities in financing are locked-in across income groups and perpetuate over time through internal market dynamics (Fig. 4). 
Escaping this lock-in particularly for international private finance is essential for developing countries ${ }^{31}$ as increasingly public finance is deployed using structures and instruments that induce private capital ${ }^{38}$. Hence, we examine the empirical nature of this path-dependency to understand the impact of cumulative installed capacity in a given country on the probability of receiving private investment. Probabilities are calculated by assigning each country a unique term that captures the combined effect of investment suitability and path-dependence (Methods). We observe that in both wind and solar technologies the probability of private investment remains low until a significant capacity base is installed. Investment probabilities start increasing rapidly around 1GW of installed capacity (Fig. 5). Path-dependency appears to be unrelated to the size of the power sector in a country (Fig. S3 shows no correlation between the relative probability of private investment and the share of renewables in the electricity mix), indicating that an investment track record depends on absolute, rather than relative, capacity levels in line with technological learning processes more generally ${ }^{39}$. Crucially, LI countries fall far below this threshold, highlighting the inefficiency of opening new finance channels in poorer nations without the sustained investment which can mobilize private finance at scale.
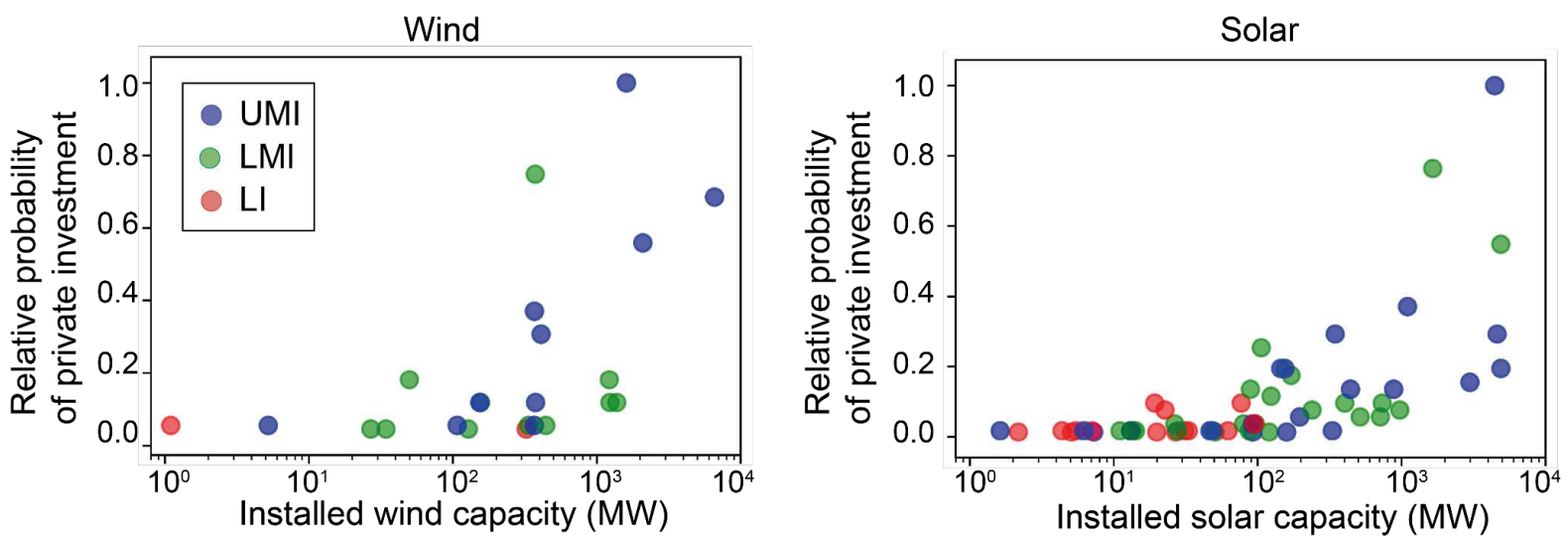

Fig. 5: Empirical relationship between relative probability of private investment and installed wind and solar capacity. Plots show the relative probability of private investment for each country against installed capacity. Probabilities are normalised against the country with the highest probability of private investment (wind: Argentina, solar: Mexico). Upper middle income (UMI), lower middle income (LMI) and low income (LI).

\section{Discussion}

During the recent COP26 climate conference, developing countries made it clear that further climate commitments and increased cooperation will depend on the delivery of "adequate and reliable finance" to meet current NDC targets and adaptation needs ${ }^{40}$. The present pledge of $\$ 100$ billion of annual financing for developing countries is much smaller than what they need - Africa alone needs $\$ 3$ trillion by $2030^{41}$. Developing countries demanded a scaled-up finance package at the COP26 that exceeds the $\$ 100$ billion per year up to 2025 , and set a post-2025 
climate finance mobilisation goal of at least $\$ 1.3$ trillion by 2030 reflecting increased climate ambition $^{42}$. Additionally, they call for fairness, transparency, and predictability in the delivery of finance as well as improved access to finance for poor and vulnerable nations.

In this context, our analysis provides evidence on the distribution of non-aid climate finance across developing countries by focusing on two highly relevant and competitive renewable energy technologies. It confirms the disparity that poorest countries have highlighted in obtaining the necessary finance ${ }^{16}-\mathrm{LI}$ countries receive a very small proportion of flows from both public and private sector, while even LMI countries struggle to attract private finance. Future commitments on climate finance thus need to consider the distributional aspects of these flows. Beyond new quantified targets, channels of financing and institutional structures need to be evaluated in terms of their suitability and capacity to mobilize finance to LI and LMI countries, and to build an effective climate finance landscape that meets these countries' needs ${ }^{43}$.

Our analysis highlights what constitutes an effective "enabling environment" for attracting longterm capital ${ }^{43}$. We show that investment suitability is based on macroeconomic capabilities, business environment, climate policy environment and electricity access levels. While all these factors play a significant role in attracting private finance, strong climate policies, such as renewables support, and efficient business practises can deliver short-term improvements, whilst economic development and electricity access programmes advance over the medium to long term. International mechanisms need to mitigate any shortcomings on these aspects, such as for countries that cannot implement strong supportive packages, to improve the riskreward balance in more equitable directions. The Sustainable Renewables Risk Mitigation Initiative of the World Bank, for instance, uses a combination of public finance and mitigation instruments to reduce risk and thereby the cost of capital ${ }^{44}$. Such programmes need a more comprehensive remit and dedicated funding. In addition, our analysis highlights the link between mitigation finance and adaptation efforts - building physical and economic resilience against climate impacts improves investment prospects.

Our analysis also shows that building a track record of investments is key to mobilising private finance at scale. Thus, public finance decisions should move beyond project-specific inducements to support more holistic renewable roadmaps to attract sustained private finance and unlock developmental co-benefits ${ }^{45}$. Innovative financial and policy mechanisms should target the evolution of the sector and build networks of relationships to initiate path-dependent flows from private sources ${ }^{46}$. On the other hand, the ethos of the wider financial community needs to shift; the rules of the game that determine investment suitability should incorporate 
climate benefits in investment decisions to lower cost of capital and improve access for developing countries. Achieved through economic incentives, legislation or investor pressure, wider participation of financial actors in investing in developing countries ${ }^{47}$ can disrupt pathdependent processes and alter the allocation of financial capital.

Finally, the relationship between the goal of Article 2.1(c) of the Paris Agreement to align financial flows with climate goals, and that of Article 9 to provide climate finance to developing countries, has been a tricky one ${ }^{11}$. Developed countries hope that financial alignment with climate goals will spur the achievement of climate finance commitments to developing countries, particularly through private sector instruments; while developing countries hope that the provision of climate finance will help them engage better with global finance. The distributional issues identified in this paper highlight that neither of these processes will work for all developing countries without supporting mechanisms at domestic and international level. Investment unsuitability will continue to hinder a climate-aligned financial system in poorer countries and path-dependency will perpetuate inequalities in climate finance allocations. These considerations need adequate attention as the work on long-term climate finance, instituted as part of the Glasgow Climate Pact ${ }^{43}$, presents its inputs at COP27. This conference being organized in the African continent represents an opportunity to deliver further climate finance commitments, based on the principle of equity, that meet the needs and priorities of developing countries. 


\section{Methods}

\section{Data Description}

Our data comes from the Bloomberg New Energy Finance (BNEF) database, which reports financial transactions on low-carbon assets between 2000 and 2019. From this database we selected a dataset of wind and solar project developments in which finance flowed across borders into a developing country of the Global South. The projects included in the dataset could be financed by multiple investors, with at least one investor being 'international' i.e., located outside of the country where the project was developed. Project information included the date of close of the transaction, geographical location, and capacity. The dataset was augmented by categorising each investor as either a public or private actor (see SI for further details). BNEF does not provide financial transaction values for all data points, we therefore used project capacity as a measure of finance flows. The costs of wind and solar technologies have dropped considerably over the last decade, so project capacity is not a wholly accurate proxy for investment value but is nonetheless fit for our purpose of assessing large-scale changes in volumes of financial flows over time and the distribution of finance across countries. It is also an indicator of the capacity of sustainable energy created in a country and thus the mitigation impact of financial flows. To analyse and compare public and private sector activity, as well as the response of public and private actors to the Paris agreement, the dataset was partitioned into 4 subsets. Firstly, between publicly and privately funded projects and secondly into a pre-Paris period (2010-2016) and a post-Paris period (2016-2019). If a project was funded by public and private actors it appeared in both data subsets and the project capacity was attributed half to public sources and half to private sources, as a commonsense approximation capturing the notion of 'risk-sharing' between investors. Further analysis capturing technology-specific aspects required partitioning each data subset into wind or solar projects.

\section{Conditional logit model: network evolution as discrete choice}

To analyse the drivers and dynamics of public and private finance flows we construct temporal networks from the project data. The networks are directed and bipartite, comprising two independent sets of nodes; international investors (source nodes) and the countries in which they invested (target nodes). Where multiple investors were involved in one project they were considered together as a single source node. The temporal evolution of the networks can be fully defined through a list of time-stamped network edges or 'action log' (Table 2).

\begin{tabular}{|l|l|l|l|l|l|}
\hline Source & Source Type & Target & Year & Sector & Funding Type \\
\hline KfW & Public & Egypt & 2010 & Wind & Public \\
\hline International Finance Corp & Public & Thailand & 2011 & Solar & Public \\
\hline
\end{tabular}




\begin{tabular}{|l|l|l|l|l|l|}
\hline African Development Bank & Public & Morocco & 2012 & Solar & Mixed \\
\hline
\end{tabular}

Table 2. Example action log. Toy data representing an action log of public investments in wind and solar assets in the pre-Paris period (2010-2015).

We use a discrete choice framework to model network evolution ${ }^{48}$. By separating public from private investors in the networks we assume a primary source of investor heterogeneity is accounted for and the investor nodes in each network can be treated as equivalent. We thus focus on the question of which country $j$ is chosen, rather than which investor $i$ does the choosing and take the conditional logit model as the most appropriate formalism. The action log for each network represents a set of choices $(j, C, t)$ where country $j$ is chosen from the set $C$ of all possible alternatives based on the features of $j$ at time $t$. $C$ is defined as the set of all countries that received public or private funding in the given time period (pre- or post-Paris).

In the conditional logit model, each country node $j \in C$ has an inherent utility to each investor $i$ which can be expressed as a linear function of its features, $x_{j}$ :

$$
u_{i j t}=\theta^{T} x_{j t}
$$

for some parameter vector $\theta$ which is fixed across countries and is time-invariant. Importantly, the features can evolve over time and are thus indexed with a timestamp $t$. The conditional logit model assumes that investors make choices by maximising the observed random utilities $U_{i j t}$ of countries which are composed of their inherent utility and a noise term $\varepsilon_{i j t}$ such that $U_{i j t}=u_{i j t}+\varepsilon_{i j t}$. The probability $P_{i}(j, C, t)$ of $i$ choosing $j$ from the choice set $C$ at time $t$ is given by

$$
P_{i}(j, C, t)=\operatorname{Pr}\left(j=\arg \max _{l \in C} U_{j l t}\right)
$$

It can be shown that when the $\varepsilon_{i j t}$ follow the standard Type I extreme value distribution the probability of choosing each alternative is proportional to the exponentiated inherent utility ${ }^{48}$ :

$$
P_{i}(j, C, t)=\frac{\exp \theta^{T} x_{j t}}{\sum_{l \in C} \exp \theta^{T} x_{l t}} .
$$

Fixed-effects models: determining the drivers of investment

To determine the drivers of public and private investment pre- and post-Paris, a number of different features, $x_{j t}$, were tested as measures of a country's utility, analogous to 'fixedeffects' in econometric analyses. Of all the features tested (Table S2), 7 were found to be 
significant drivers of investment activity across the networks (Fig. 2). These features can be divided into two classes: those relating to a country's suitability for investment (EF, EDB, RISE and Elec Access) and those relating to a country's level of installed capacity (LogCap Pub, LogCap Pri and LogCap Tot). The investment suitability features were taken from public sources and scaled for each network to fall between 0 and 1 , so that coefficients are comparable. The capacity level features were constructed from the BNEF data, for example, the value of LogCap Pub $\mathrm{Pu}_{j t}$ was calculated as the logarithm of the cumulative installed capacity in country $j$ from public sources between 2000 and the year $t-1$. Taking the logarithm of the cumulative installed capacity connects the three conditional logit models based on capacity level features to the popular preferential attachment model of network growth ${ }^{49}$, which is itself a special case of the conditional logit model where the utility $u_{i j}=\alpha \log d_{j}$ with $d_{j}$ is the degree of node $j$. The capacity level features thus capture the same 'rich-get-richer' phenomenon that preferential attachment describes, in which attachment probability is proportional to a power-law function of node degree. Modelling the wind and solar data together (see main text) and separately (Table S2) gave similar key results with private sector activity driven by the investment suitability features and capacity level features and public sector activity driven mainly by the latter.

\section{Random-effects model: estimating country-specific investment probabilities}

To explore the relationship between the level of installed wind (solar) capacity and the probability of a wind (solar) investment on a country-by-country basis (Fig. 5), we also developed a set of 'random-effects' models in which a unique time-invariant parameter $\theta_{j}$ was assigned as each country's utility such that $u_{i j}=\theta_{j}$. The random-effect term captures the combined effect of the investment suitability features and the capacity level features, which may include idiosyncratic interaction terms and non-linearities, as well as other relevant features that were not tested in our study. These 'random-effect' models could then be used to precisely capture technology-specific investment probabilities for each country using

$$
P_{i}(j, C, t)=\frac{\exp \theta_{j}}{\sum_{l \in C} \exp \theta_{l}}
$$

\section{Parameter estimation}

We used a maximum likelihood approach to estimate the model parameters. For the fixedeffect models the log-likelihood of the choice data $\mathrm{D}$ conditional on $\theta$ is given by,

$$
L(\theta ; \mathrm{D})=\sum_{(j, C, t) \in \mathcal{D}} \log \frac{\exp \theta x_{j t}}{\sum_{(l, C, t) \in \mathrm{D}} \exp \theta x_{l t}} .
$$


This log-likelihood function is convex with respect to the parameter $\theta$ and can be efficiently maximised using the gradient-based BFGS algorithm ${ }^{48}$.

For estimation of the country-specific utilities in the random-effect models in which $u_{i j}=\theta_{j}$, , we make the connection between our discrete choice framework and the 'fitness' model of network growth in which attachment probability is proportional to an inherent node fitness $p_{i j} \sim$ $\lambda_{j}$ by making the equivalence $\lambda_{j}=\exp \theta_{j}$. Following the work of Pham et al. ${ }^{50}$ in which the fitness parameters are drawn from a Gamma distribution we add a regularization term $S=$ $\sum_{(j, C, t) \in D}-\log \Gamma(k)-k \log t+(k-1) \log \theta_{j}-\frac{1}{t} \theta_{j}$ to the log-likelihood, equivalent to placing a Bayesian gamma prior with shape parameter $k$ and scale parameter $t$ onto the likelihood function. The log-likelihood is thus given by,

$$
L(\theta ; \mathrm{D})=\sum_{(j, C, t) \in \mathrm{D}} \log \frac{\exp \theta_{j}}{\sum_{(l, C, t) \in \mathrm{D}} \exp \theta_{l}}+S
$$

The standard deviation of parameter estimates is calculated by inverting the variancecovariance (Hessian) matrix of the log-likelihood function.

\section{Model evaluation}

To assess the statistical significance of each feature in the fixed-effects models we used the likelihood-ratio test, comparing the likelihood of the estimated model $L_{1}$ against the likelihood of the equivalent null model $L_{0}$ with the parameter $\theta$ set to 0 . The likelihood ratio $\lambda=L_{0} / L_{1}$, under some regularity conditions, is asymptotically distributed ${ }^{48}$ as

$$
-2 \log \lambda \sim \chi_{1}^{2}
$$

and $p$-values can be found using this likelihood-ratio chi-square statistic.

As an additional metric of feature significance, we assessed model accuracy by simulating network evolution and using Spearman's correlation coefficient to compare the empirical distribution of investments across countries and the average of 20 simulated distributions. A coefficient of 1 thus indicates a given feature perfectly captures the investment activity, while a coefficient of 0 indicates a feature does not perform better than the null model. Accuracy scores were also used to assess the random-effects models; scores of 0.6 and above were sought by optimising the scale and rate parameters of the regularization term S (Table S4) to obtain estimates from country-specific utilities (Table S5). 


\section{Data availability}

The results data, figure data and publicly sourced data are provided with this paper and the supplementary materials. The project-level dataset used to generate the results is proprietary to BNEF and cannot be made publicly available. On obtaining access to the data, the protocols detailed in the Supplementary Information can be used to reproduce the results of this study.

\section{Code availability}

All model code used to generate results for this article is archived and freely available at https://github.com/LINKS-ERC/The_Unequal_Distribution_of_Climate_Finance.

\section{References}

1. Report of the Conference of the Parties on its fifteenth session, held in Copenhagen from 7 to 19 December 2009. 2010, United Nations, General Assembly.

2. Report of the Conference of the Parties on its twenty-first session, held in Paris from 30 November to 13 December 2015. 2010, United Nations, General Assembly.

3. United Nations Framework Convention on Climate Change. 1992, United Nations, General Assembly.

4. Wilkinson, J. and J. Flasbarth, Climate Finance Delivery Plan: Meeting the US\$100 Billion Goal. 2021.

5. Weikmans, R. and J.T. Roberts, The international climate finance accounting muddle: is there hope on the horizon? Climate and Development, 2019. 11(2): p. 97-111.

6. Roberts, J.T., et al., Rebooting a failed promise of climate finance. Nature Climate Change, 2021. 11(3): p. 180-182.

7. McCollum, D., et al., Energy investments under climate policy: a comparison of global models. Climate Change Economics, 2013. 4(04): p. 1340010.

8. First report on the determination of the needs of developing country Parties related to implementing the Convention and the Paris Agreement. 2021, UNFCCC Standing Committee on Finance.

9. GCF at a glance. 2021, Green Climate Fund.

10. Yeo, S., Where climate cash is flowing and why it's not enough. Nature, 2019. 573(7774): p. 328-332.

11. Zamarioli, L.H., et al., The climate consistency goal and the transformation of global finance. Nature Climate Change, 2021. 11(7): p. 578-583.

12. Climate Finance Provided and Mobilised by Developed Countries in 2013-18. 2020, OECD.

13. Global finance ministers gather to discuss how public and private finance can lead the transition to a net zero, climate resilient world. 2021, UN Climate Change Conference UK 2021.

14. Net Zero Financing Roadmaps. 2021, UNFCC Race to Zero.

15. Carney, M., Building a private financial system for net zero. 2021.

16. Delivering on the $\$ 100$ billion climate finance commitment and transforming climate finance. 2020, Independent Expert Group on Climate Finance.

17. Global Landscape of Climate Finance 2021. 2021, Climate Policy Initiative.

18. The Glasgow Financial Alliance for Net Zero. 2021, GFANZ. 
19. Fourth (2020) Biennial Assessment and Overview of Climate Finance Flows. 2020, UNFCCC Standing Committee on Finance.

20. World Bank Country and Lending Groups. Available from: https://datahelpdesk.worldbank.org/knowledgebase/articles/906519-world-bankcountry-and-lending-groups.

21. Climate Scope Emerging Markets Outlook 2020. 2020, Bloomberg Finance.

22. Zaccaria, A., et al., Integrating services in the economic fitness approach. World Bank Policy Research Working Paper, 2018(8485).

23. Mundial, B., Doing Business 2020. Washington, DC: World Bank. DOI, 2020. 10: p. 978-1.

24. Banerjee, S.G., et al., Regulatory Indicators for Sustainable Energy. 2017.

25. Access to electricity (\% of population). Available from: https://data.worldbank.org/indicator/EG.ELC.ACCS.ZS.

26. Chen, C., et al., University of Notre Dame global adaptation index country index technical report. ND-GAIN: South Bend, IN, USA, 2015.

27. Renewable Power Generation Costs in 2020. 2020, IRENA.

28. Climate Change 2021: The Physical Science Basis. Contribution of Working Group I to the Sixth

Assessment Report of the Intergovernmental Panel on Climate Change. 2021, IPCC.

29. Ameli, N., et al., Higher cost of finance exacerbates a climate investment trap in developing economies. Nature Communications, 2021. 12(1): p. 1-12.

30. Volz, U., J., et al., Climate Change and Sovereign Risk. 2020, SOAS University of London, Asian Development Bank Institute, World Wide Fund for Nature Singapore, and Four Twenty Seven.

31. Climate Investment Opportunities in Emerging Markets. 2016, International Finance Corporation

32. Mazzucato, M. and C.C. Penna, Beyond market failures: The market creating and shaping roles of state investment banks. Journal of Economic Policy Reform, 2016. 19(4): p. 305-326.

33. Geddes, A., T.S. Schmidt, and B. Steffen, The multiple roles of state investment banks in low-carbon energy finance: An analysis of Australia, the UK and Germany. Energy Policy, 2018. 115: p. 158-170.

34. Arthur, W.B., Positive feedbacks in the economy. Scientific american, 1990. 262(2): p. 92-99.

35. Arthur, W.B., Competing technologies, increasing returns, and lock-in by historical events. The economic journal, 1989. 99(394): p. 116-131.

36. Egli, F., B. Steffen, and T.S. Schmidt, A dynamic analysis of financing conditions for renewable energy technologies. Nature Energy, 2018. 3(12): p. 1084-1092.

37. Griffith-Jones, S. and G. Cozzi, 5. The Roles of Development Banks: How They Can Promote Investment in Europe and Globally, in Efficiency, Finance, and Varieties of Industrial Policy. 2016, Columbia University Press. p. 131-155.

38. Chavarot, A. and M. Konieczny, Mobilizing Private Sector Capital for Low-Carbon Investments in Developing Countries, in Renewable Energy Finance: Funding The Future Of Energy. 2020, World Scientific. p. 171-196.

39. Nagy, B., et al., Statistical basis for predicting technological progress. PloS one, 2013. 8(2): p. e52669.

40. Statement on behalf of the group of 77 and China at the join plenary meeting of conference of the parties (COP26). Available from:

https://www.g77.org/statement/getstatement.php?id=211031. 
41. A five-point plan for solidarity, fairness and prosperity. 2021, COP26 Delivering the Paris Agreement.

42. Conference Room Paper: Group of Like Minded Developing Countries and the African Group of Negotiators. 2021, The Conference of the Parties

43. Decision -/CP.26 Long-term climate finance. 2021, The Conference of the Parties

44. Sustainable Renewables Risk Mitigation Initiative (SMRI). Available from: https://www.worldbank.org/en/topic/energy/brief/srmi.

45. Schwerhoff, G. and M. Sy, Financing renewable energy in Africa-Key challenge of the sustainable development goals. Renewable and Sustainable Energy Reviews, 2017. 75: p. 393-401.

46. Ameli, N., S. Kothari, and M. Grubb, Misplaced expectations from climate disclosure initiatives. Nature Climate Change, 2021. 11(11): p. 917-924.

47. Arezki, R., Climate finance for Africa requires overcoming bottlenecks in domestic capacity. Nature Climate Change, 2021. 11(11): p. 888-888.

48. Overgoor, J., A. Benson, and J. Ugander. Choosing to grow a graph: modeling network formation as discrete choice. in The World Wide Web Conference. 2019.

49. Jeong, H., Z. Néda, and A.-L. Barabási, Measuring preferential attachment in evolving networks. EPL (Europhysics Letters), 2003. 61(4): p. 567.

50. Pham, T., P. Sheridan, and H. Shimodaira, Joint estimation of preferential attachment and node fitness in growing complex networks. Scientific Reports, 2016. 6(1): p. 113.

\section{Acknowledgements}

This project has received funding from the European Research Council under the European Union's Horizon 2020 research and innovation programme (grant agreement number 802891). The authors would like to thank Prof Yacob Muguletta and Prof Michael Grubb for their valuable comments and suggestions which helped us to improve the quality of the manuscript.

\section{Author Information}

Institute for Sustainable Resources, University College London, London, UK Jamie Rickman, Sumit Kothari, Francesca Larosa \& Nadia Ameli

\section{Author Contributions}

J. R. and N. A. designed the study with input from S. K. and F.L.. J. R. coordinated the research and undertook the analysis and modelling. S. K. framed the results and wrote the manuscript with J. R., with input and review from F. L. and N. A..

\section{Ethics declarations}

Competing Interests

The authors declare no competing interests. 


\section{Supplementary Files}

This is a list of supplementary files associated with this preprint. Click to download.

- SupplementaryMaterialsFigureData.xIsx

- SupplementaryInformation.docx

- SupplementaryMaterialsFeatureData.xls 